\title{
The Wealth Effect Of The Stock Market Revisited
}

Hassan Shirvani, (Email: shirvani@stthom.edu), University of St. Thomas Barry Wilbratte, (Email: wilbratt@stthom.edu), University of St. Thomas

\begin{abstract}
This paper provides evidence that wealth in the form of stock ownership affects consumption and that the stock wealth effect has increased significantly. Using a consumption function expanded to include wealth as well as income, the paper first confirms that the data indicate the presence of a wealth effect. Then, the paper tests for a break in the relationship and finds that for stock wealth only, the consumption coefficient increased in the early 1990s. (JEL: E2, G1)
\end{abstract}

\section{Introduction}

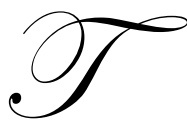

he remarkably sharp increase in the level of stock prices in recent years has once again heightened the interest of government policymakers and macroeconomists in the importance of the stock market to the economy. In particular, the Federal Reserve has focused its attention on the stock market as a potential source of instability to the economy through the wealth effect. Although the wealth effect of rising stock prices has been beneficial to date, the possibility of further increases poses the risk of a rising inflation rate. The opposing concern, of course, is that stock prices may fall further, lowering consumption and resulting in an economic downturn. Indeed, our own evidence (Shirvani and Wilbratte, 2000) indicates that a fall in stock prices exerts a more powerful effect than a rise, thus heightening the importance of this possibility. An additional concern is that rising stock values seem to have contributed to a sharp decline in personal savings in recent years, possibly as a consequence of the effects of rising stock values on consumption. Presumably, this occurred as a result of households' treating the growth in their wealth through rising stock prices as a substitute for savings from current income. Thus, the attention to stock valuations seems to be warranted, especially since the increase in stock prices in the 1990s has been coupled with an unprecedented increase in the breadth of stock ownership by the American public.

Stock wealth in the U. S. has grown rapidly for nearly two decades. Between 1982 and 1998, the total value of equities in the U. S. increased eightfold. This measure encompasses all forms of stock wealth including mutual funds and retirement accounts. However, the increased breadth of ownership is a more recent phenomenon. After remaining stable from 1983 through 1989 at less than 32 percent, the proportion of families owning stock rose sharply in the 1990s, reaching nearly 50 percent in 1998 (Federal Reserve Bulletin). We would expect both of these phenomena to have decreased the proportion of current income saved and rendered the economy more vulnerable to fluctuations in stock prices. In addition, the widening of the distribution of ownership in the 1990s may have increased the impact of a given change in stock values on consumption. In other words, whereas both the growth of stock valuations and the wider spread of ownership may have strengthened the impact of stocks on the economy, only the latter can be expected to have altered the coefficient relating consumption to stock wealth.

The changing role of the stock wealth effect on consumption is reflected in research of the past several decades. In an early study, Arena $(1964,1965)$ finds that the effects of stock market gains on consumption are low and perhaps zero, a result he attributes to the narrowness of public ownership at the time of his study. Similarly, Hymans' (1970) findings cast further doubt on the role of stocks in the consumption function. Subsequently, however, studies by Bosworth (1975), Hall (1978), Starr-McCluer (1998), and Ludvigson and Steindel (1999) have provided evidence that stock wealth significantly contributes to consumer spending through a wealth effect. On the other hand, Poterba and Samwick (1995) find evidence that stock price changes affect consumer spending not through a wealth effect but rather by acting as economic indicators.

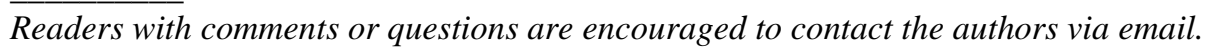


Using data and methods more current than most of these studies, we find not only that there is a stock wealth effect on consumption but that it has strengthened in recent years. Using cointegration estimation techniques, the present study successfully incorporates stock wealth into the consumption function, lending more robust statistical confirmation to the validity of earlier findings, most of which employ simple regression analysis. As is well known, simple regression in the context of nonstationary data is not justified, as the resulting test statistics will have nonstandard distributions. Under these conditions, it is necessary to employ cointegration techniques to obtain more reliable estimates. In addition, we test whether the relationship between consumption and stock wealth has shifted over time. As discussed later in the paper, the resulting estimates show that such a shift has indeed occurred. The strengthening of the wealth effect in the 1990s can be explained in terms of the increased breadth of stock ownership, which would explain our finding of an increased stock wealth coefficient of consumption.

This paper employs a standard consumption model which expresses consumer spending as a function of labor income, stock wealth, and nonstock wealth. The formal expression of the model is as follows:

$$
\mathrm{C}_{\mathrm{t}}=\mathrm{a}+\mathrm{bY_{ \textrm {t } }}+\mathrm{cS}_{\mathrm{t}}+\mathrm{dNS}_{\mathrm{t}}+\varepsilon_{\mathrm{t}}
$$

where $\mathrm{C}=$ personal consumption expenditure, $\mathrm{Y}=$ labor income, $\mathrm{S}=$ stock wealth, and $\mathrm{NS}=$ nonstock wealth. All variables are expressed as levels in real per capita terms. (See Data Appendix for more complete descriptions.) The observations are quarterly and span the period 1952:1 to 1997:4.

The separation of the stock from nonstock forms of wealth is justified on the grounds that the two variables have behaved in significantly different fashions and have surely affected consumption differently. Stocks have appreciated faster and been more volatile than other assets, and the increase in the breadth of their ownership in the key period of the 1990s further differentiates them from other assets. In addition, given the greater volatility of stock prices relative to nonstock forms of wealth, it is expected that the perceived transitory nature of the changes in their values would have smaller impact on consumption than similar changes in the values of other assets. Empirically, this means that we should get a smaller marginal propensity to consume coefficient for stocks than for other wealth. Finally, since stock wealth tends to be held by wealthier households, the MPC of stock wealth may be smaller than the MPC of wealth in general.

Since the tests to be reported later in the paper imply that the variables in equation 1 are nonstationary, the equation is estimated as the long-run relationship between consumption and its determinants using the cointegration method. To test for short-term adjustments to equilibrium, we employ the following error correction equation:

$$
\Delta C_{t}=\mu+\sum_{i=1}^{k} \alpha_{i} \Delta Y_{t-i}+\sum_{i=1}^{k} \beta_{i} \Delta S_{t-i+} \sum_{i=1}^{k} \gamma_{i} \Delta N S_{t-i}+\sum_{j=1}^{r} \phi_{j}\left(E C M_{j}\right)_{t-1}+v_{t}
$$

where $\mathrm{k}$ is the appropriate number of lags employed in estimating the error correction equation, $\mathrm{r}$ is the number of cointegrating vectors, and ECMs are the error correction terms associated with the cointegrating vectors.

To determine the time series properties of the underlying data, we perform Phillips-Perron (1988) unit root tests against the null of stationarity around a trend. The results are reported in Table 1. As required for the cointegration estimates, the test results indicate that our underlying data are integrated of order one. Accordingly, equation 1 serves as our cointegrating equation.

Table 1

Phillips Perron Unit Root Test Results

\begin{tabular}{cccc}
\hline Variable & $\underline{\text { Value }}$ & $\underline{\text { Variable }}$ & $\underline{\text { Value }}$ \\
\cline { 2 - 3 } & -2.54 & $\Delta \mathrm{C}$ & $-9.71 *$ \\
$\mathrm{Y}$ & -1.90 & $\Delta \mathrm{Y}$ & $-14.57^{*}$ \\
$\mathrm{~S}$ & 1.54 & $\Delta \mathrm{S}$ & $-12.09 *$ \\
$\mathrm{NS}$ & -1.62 & $\Delta \mathrm{NS}$ & $-8.13 *$ \\
\hline
\end{tabular}

* indicates significant at the 1 percent level. 
In testing for cointegration, we apply the Johansen and Juselius (1990) multivariate approach. The first step in our tests is to determine the appropriate lag length using the procedure provided by Perron and Vogelsang (1992). We begin with a lag length of 6 quarters and, using the likelihood ratio, test downward until reducing the lag length by one period is rejected. The test results indicate that a lag length of 4 quarters is appropriate.

The Johansen-Juselius cointegration test results appear in Table 2. Although clearly indicating that there is one cointegrating vector, the results are mixed in terms of the level of significance. The more powerful maximum eigenvalue test indicates significance at the .01 level, whereas the trace test indicates significance at the .10 level. In addition, all coefficients are appropriately signed and of reasonable values. To buttress this finding, we repeat our estimation of the cointegrating equation using the Stock-Watson (1993) dynamic OLS estimation procedure, in which the level of consumption is regressed on the current levels of the independent variables as well as the past and future changes in these variables. This procedure, which is appropriate in the present context of only one cointegrating vector, is asymptotically equivalent to the Johansen-Juselius method and, as expected, yields highly similar cointegrating coefficients. The estimated cointegrating equations from the two methods are as follows:

$$
\begin{array}{ll}
\text { Johansen-Juselius: } & \mathrm{C}_{\mathrm{t}}=.69 \mathrm{Y}_{\mathrm{t}}+.024 \mathrm{~S}_{\mathrm{t}}+.053 \mathrm{NS}_{\mathrm{t}} \\
\text { Stock-Watson: } & \mathrm{C}_{\mathrm{t}}=.72 \mathrm{Y}_{\mathrm{t}}+.022 \mathrm{~S}_{\mathrm{t}}+.053 \mathrm{NS}_{\mathrm{t}}
\end{array}
$$

Relying on the Johansen-Juselius and Stock-Watson estimates, we establish the statistical significance of the coefficients using, respectively, $\chi^{2}$ and $t$ tests. With one degree of freedom in the $\chi^{2}$ test, each variable is statistically significant, as reported in Table 2 . More specifically, the stock wealth coefficient is significant at the .05 lev$\mathrm{el}$, and all other variables significant at the .01 level. The $t$ test in the context of Stock-Watson (not reported) indicates that all variables are significant at the .01 level. It is noteworthy that our total wealth coefficients of roughly .075 are at the high end of the range of estimates, whereas our stock coefficients are lower than the nonstock coefficients, as expected.

Table 2

\begin{tabular}{|c|c|c|c|c|c|}
\hline \multicolumn{4}{|c|}{ Maximum Eigenvalue } & \multicolumn{2}{|c|}{ Chi-squared test } \\
\hline \multicolumn{2}{|c|}{ Test } & \multicolumn{2}{|c|}{ Trace test } & Variable & $\chi^{2}(1)$ \\
\hline $\mathrm{r}=0$ & $31.55^{*}$ & $\mathrm{r}=0$ & $46.27 * * *$ & $\mathrm{C}$ & $15.76 *$ \\
\hline $\mathrm{r} \leq 1$ & 8.91 & $\mathrm{r}=1$ & 14.72 & Y & $19.62 *$ \\
\hline $\mathrm{r} \leq 2$ & 4.93 & $r=2$ & 5.81 & $\mathrm{~S}$ & $4.01 * *$ \\
\hline$r \leq 3$ & 0.88 & $\mathrm{r}=3$ & 0.88 & NS & $8.4 * *$ \\
\hline
\end{tabular}

Cointegration Test Results, Equation 1

$*, * *$ and $* * *$ indicate significant at the $.01, .05$, and .10 levels, respectively.

Having established cointegration and the statistical significance of the cointegrating coefficients, we test for the temporal stability of these coefficients in the 1990s, relying on procedures developed by Hansen and Juselius (1995) and Chow (1960). The purpose of these tests is to determine whether there has been a shift in the long-run relation of consumption to stock wealth (and possibly other variables as well) in the 1990s. Conceivably, a break occurred in the 1990s, which is related to events specific to this period and therefore not permanent. Suppose, for instance, households that have newly entered the stock market in response to the strong run-up in prices will exit the market in the event of a protracted sell-off. This would constitute a short-term break, which does not affect the long run cointegrating coefficients.

Indeed, our statistical tests indicate that this is the case. Specifically, in the context of the JohansenJuselius cointegration estimates, we apply the Hansen and Juselius test, first estimating the coefficients from the beginning of the sample period through 1991:3 (a date which lies between the beginning of the economic recovery from the recession of 1990-1991 and our first data point indicating a widening in the spread of stock ownership), and then successively adding observations for the remainder of the sample period to test whether the full-sample coefficient estimates, reported earlier, belong to the same cointegration space as the sequential subsample estimates. The Hansen-Juselius test statistic, which follows a $\chi^{2}$ distribution, is scaled by the 95 percent quintile such that unity corresponds to the 5 percent significance level. Our estimated $\chi^{2}$ value never exceeds 0.4 , indicating no signifi- 
cant change in the cointegrating coefficients in the 1990s. Likewise, we apply the Chow test in the context of the Stock-Watson cointegration test to determine whether the estimated cointegration equation for the subsample 1952:1-1991:3 remains stable for the balance of the sample period. We accomplish this by introducing one dummy variable corresponding to each explanatory variable. The dummy variables assume values of 1 after 1991:3 and 0 otherwise. This test yields an $\mathrm{F}$ value of 2.10 , which is not statistically significant even at the .10 level. We therefore accept the null that the dummy coefficients are zero, confirming that there is no break in the cointegrating coefficients in the 1990s. This evidence indicates that if there proves to be a break in the 1990s, we should conclude that the break is transitory rather than permanent.

To test for the presence of a short-run break in the consumption function, we rely on the error correction equation associated with the above cointegrating relationship. As is well known, error correction equations capture the short-run adjustments of the dependent variable to changes in the independent variables as well as to any departures from long-run equilibrium. Under these conditions, the short-run stability test is a Chow test which parallels the long-run test previously described. Before conducting the Chow test, however, we ascertain that the estimated error correction equation passes the standard diagnostic tests. As Table 3 indicates, the Ljung-Box statistic indicates no serial correlation of higher order, a fourth-order ARCH test indicates no autoregressive conditional heteroscedasticity, and the adjusted coefficient of determination equals 0.26 . Finally, the F statistic of overall goodness of fit is significant at 1 percent.

Table 3

Diagnostics of error correction equation

\begin{tabular}{|c|c|c|c|c|c|c|}
\hline \multicolumn{2}{|c|}{$\begin{array}{l}\text { Ljung-Box } \\
\text { chi-squared test }\end{array}$} & \multicolumn{2}{|c|}{ Arch test } & \multirow{2}{*}{$\begin{array}{l}\text { Adjusted } \\
\text { R-squared }\end{array}$} & \multicolumn{2}{|c|}{ F test of goodness of fit } \\
\hline size & p-value & size & p-value & & size & $\mathrm{p}$-value \\
\hline 40.4 & 0.28 & 0.42 & .79 & 0.26 & 175.94 & .01 \\
\hline
\end{tabular}

The $\mathrm{F}$ value for the Chow test of short term break in the error correction equation is 87.9 , significant at the .01 level, indicating rejection of the null hypothesis that the dummy variables are zero and thus indicating that there is indeed a break in the short-run relationship between consumption and its determinants.

Given the evidence that a break has occurred, we perform t-tests of the significance the sum of the lagged coefficients of the changes in the independent variables to determine which of these variables has significantly contributed to the short-term break. The test results of this equation, reported in Table 4, indicate a significant positive change of roughly 0.012 in the cumulative stock coefficient (from 0.018 prior to the 1990 s to 0.030 in the 1990s) of the error correction equation, with negative but insignificant changes in the income and nonstock wealth coefficients. We conclude from this short-run evidence that the decade of the 1990s has indeed been characterized by a significant increase in the short run importance of the stock wealth effect on consumption. Specifically, whereas prior to the 1990s each additional dollar of stock wealth added 1.8 cents to consumption within a year, in the 1990s the magnitude of this contribution increased to roughly 3.0 cents.

Table 4

Tests for Changes in Coefficient Sums of Error Correction Equation

\begin{tabular}{lcc}
\hline \multicolumn{2}{c}{ Tests for Changes in Coefficient Sums of Error Correction Equation } \\
\cline { 2 - 2 } Variable & \multicolumn{1}{c}{ Coefficient } \\
\cline { 2 - 3 } Y & -.078 \\
NS & $.012^{* *}$ \\
& -.025 \\
\hline
\end{tabular}

** indicates significant at the .05 level.

\section{Conclusions}

The statistical results presented in this paper lend support to earlier findings of a wealth effect associated with the equities market, but also indicate that the wealth effect has increased substantially in the 1990s. In an equa- 
tion that captures the effects of income and two measures of wealth on consumption, we find strong evidence that only the coefficient of stock wealth has increased in recent years. This latter finding is not surprising in light of the ever-wider ownership of equities that has recently characterized the United States.

Our findings with respect to the wealth effect of stocks can explain the steadily declining U.S. savings rates of the 1990s, a trend which has brought savings to remarkably low levels. The last previous experience of lower savings occurred during the Great Depression, when sharply declining income dramatically reduced households' ability to save and drove savings to negative levels. In this light, the recent combination of near-zero savings and rising incomes becomes particularly anomalous but is easily explained in terms of the increased wealth effect of stock valuations. Whereas in the earlier experience of negative savings, the negative effect of falling incomes dominated the positive effect of falling stocks on savings, the current experience clearly implies the opposite. That is, the positive effect of rising incomes on savings in recent years has clearly been dwarfed by the negative effect of rising stock prices.

Our findings further indicate that the Federal Reserve's strong vigilance with respect to the potentially destabilizing effects of stock prices on the economy is increasingly warranted, particularly in light of the recent fall in stock prices. The decline of stock prices which continued through early 2001 has yet to have its full impact on the economy. Our evidence suggests that a protracted downturn of this type could result in a drop in consumption with a significant negative impact on the economy

\section{Suggestions for Future Research}

This paper confirms the existence of a stock wealth effect and shows that it increased over time as the breadth of stock ownership grew. Several interesting extensions of this work are possible. First, it would be interesting to further examine whether the relationship between stock prices and consumption can be explained in terms of expectations rather than as a wealth effect. In addition, one could test whether there is a difference between the wealth coefficients of stocks held in retirement accounts and stocks held in nonsheltered accounts, which are more frequently traded. Conceivably, the different portfolios are held to finance different expenditures and may have different effects on consumption. It would also be interesting to determine whether the different components of consumption respond differently to wealth changes. In particular, it is conceivable that consumer durables may be more or less responsive to wealth than are nondurables and services. Finally, the huge downturn of 2000-2001 may have resulted in a change in the stock wealth coefficient because the protracted decline may have resulted in a narrowing of stock ownership. Such a change in the wealth coefficient would be revealed in an update of the present study when the data become available.

\section{Data Appendix}

Labor income is defined as wages and salaries + transfer payments + other labor income - personal contributions for social insurance - taxes. Stock wealth consists of direct household stock holdings, mutual fund holdings, holdings of private and public pension plans, personal trusts, and insurance companies, and nonstock wealth is household net wealth less stock wealth. Nominal data are deflated by the personal consumption expenditure chaintype price deflator, seasonally adjusted. All data were generously supplied by Sydney Ludvigson and Charles Steindel, of the Federal Reserve Bank of New York.

\section{References}

1. Arena, John J, "Capital Gains and the 'Life Cycle' Hypothesis of Saving," American Economic Review, Vol. 54, No. 2, Part 1, pp. 107-11, 1964.

2. CPostwar Stock Market Changes and Consumer Spending," Review of Economics and Statistics, Vol. 47, No. 4, pp. 379-91, 1965.

3. Bosworth, Barry, "The Stock Market and the Economy," Brookings Papers on Economic Activity, Vol. 2, pp. 257-300, 1975. 
4. Chow, G. C., "Tests of Equality between Sets of Coefficients in Two Linear Regressions," Econometrica Vol. 28, pp. 591-605, 1960.

5. Hall, Robert E. , "Stochastic Implications of the Life Cycle-Permanent Income Hypothesis: Theory and Evidence." Journal of Political Economy, Vol. 86, No. 6, pp. 971-87, 1978.

6. Hansen, Henrik and Katerina Juselius, Cats in Rats: Cointegration Analysis of Time Series. Estima, Evanston, Illinois, 1995.

7. Hymans, Saul H., "Consumption: New Data and Old Puzzles," Brookings Papers on Economic Activity, Vol 1, pp. 117-26, 1970.

8. Johansen, Soren and Katerina Juselius, "Maximum Likelihood Estimation and Inference on Cointegrationwith Applications to the Demand for Money." Oxford Bulletin of Economics and Statistics, Vol. 52, pp. 490502, 1990.

9. Ludvigson, Sydney and Charles Steindel, "How Important Is the Stock Market Effect on Consumption?" Bulletin, Federal Reserve Bank of New York, Vol. 85, No. 7, pp. 29-51, 1999.

10. Poterba, James M. and Andrew A. Samwick, "Stock Ownership Patterns, Stock Market Fluctuations, and Consumption." Brookings Papers on Economic Activity, Vol. 2, pp. 295-357, 1995.

11. Shirvani, Hassan and Barry Wilbratte, "Does Consumption Respond More Strongly to Stock Market Declines than to Increases?" International Economic Journal, Vol. 14, No. 3, pp. 41-50, 2000.

12. Starr-McCluer. "Stock Market Wealth and Consumer Spending," Federal Reserve Board of Governors, Finance and Economics Discussion Series, April, 1998.

13. Stock, James H. and Mark W. Watson. "A Simple MLE of Cointegrating Vectors in Higher Order Integrated Systems." Econometrica, Vol. 61, No. 4, 873-820, 1993. 